PanAfrican
8o8OMedical
\&o8journal

Research, Volume 7, number 16, 2010
Provisional PDF

Published November 272010

\title{
Predictors of emergency contraceptive use among Regular Female Students at Adama University, Central Ethiopia
}

\author{
Dejene Tilahun $^{1, \&}$, Tsion Assefa ${ }^{1}$, Tefera Belachew ${ }^{2}$ \\ ${ }^{1}$ Department of Health Promotion and Behavioral Sciences Jimma University, \\ Ethiopia, ${ }^{2}$ Department of population and Family Health, J imma University, Ethiopia
}

\author{
${ }^{\&}$ Corresponding author \\ Dejene Tilahun, In the Department of Health Promotion and Behavioral Sciences Jimma \\ University, Tel +25191811301, Ethiopia
}

\begin{abstract}
Background: One of the key interventions to reduce unintended pregnancy and unsafe abortion outlined in the national youth strategy is availability of emergency contraception. However, there are no studies which document emergency contraception use and the factors influencing the use of emergency contraceptives among university girls in Ethiopia. This study was carried out to assess emergency contraception use and its predictor factors among regular female students at Adama University. Methods: A cross-sectional study was conducted during the month of February 2009, among randomly selected 660 female students of Adama University Central Ethiopia. Data were collected through pre-tested self-administered questionnaire. Bivariate and multivariable logistic regression models were fitted to identify variables predicting emergency contraception use. Results: One hundred ninety four (29.4\%) students were sexually active and $63(9.4 \%)$ had a previous history of pregnancy. And most of the pregnancies (92\%) were unintended. Majority $(77.7 \%)$ of pregnancies were terminated by way of induced abortions carried out by untrained persons. Only $26.7 \%$ of those who had unprotected sex used emergency
\end{abstract}


contraception. Lack of knowledge, fear of being seen by others, and inconvenient service delivery were pointed out as the main reasons for not using emergency contraceptives. Previous use of contraceptives (AOR: 1.953; 95\% Cl = 1.72- 6.345), being married (AOR: 9.254 (95\% Cl: 2.53820.73) and age of 20 years and above (AOR: 2.372; $95 \% \mathrm{Cl}=1.102-7.246$ ) were significant predictors use of emergency contraception, while poor knowledge of emergency contraception was a significant predictor of non-use of emergency contraception $\quad(A O R: 0.09 ; 95 \% \mathrm{Cl}=$ 0.041-0.189). Conclusion: The study pointed out the need for increasing the knowledge of university going young women about emergency contraception, and the need for availing youth friendly reproductive health services to promote preventive behavior.

\section{Background}

Despite the technological advancements in modern contraception methods, unintended pregnancy is still a big problem in Ethiopia [1-2]. More than $60 \%$ of the pregnancies in adolescents are unintended; ones which result from contraception non-use, contraception method failure and rape [3-4]. The incidence of unintended pregnancy and unsafe abortion, particularly among adolescents, remains high $[1,5,6]$. In Ethiopia, abortion emanating from unintended pregnancy is one of the most significant causes of maternal morbidity and mortality; it is also a major medical and public health problem $[1,2]$.

Currently, more and more young people engage in sexual activity before marriage, often without using contraception [1]. Country-specific data indicates that young women who are unmarried are increasingly sexually active before the age of 15 [7,9]. Thus unwanted pregnancy is one of the greatest problems a young girl can face; this poses major public health problems in the developed and developing countries, including Ethiopia [11, 12]. Unintended pregnancy and early child bearing impacts negatively on the educational prospects of girls by forcing them to drop out of school (jeopardizing students' educational progress and future careers) because of the morbidity resulting from unsafe abortion when the pregnancy is unwanted, culminating in poor participation of girls in the overall socio-economic development of their communities and eventually their countries $[6,7]$.

The use of emergency contraception (EC) will decrease the cost, the emotional and the physical risk experienced by women of reproductive age who engage in early sexual activity [3,7]. EC refers to the type of contraception that is used as an emergency procedure to prevent 
unintended pregnancy following an unprotected act of sexual intercourse or contraception failure [7].

There are four forms of EC methods used as emergency contraceptives: Levonorgestrel (LNG)only regimen. $0.75 \mathrm{mg}$ LNG (or $1.5 \mathrm{mg}$ norgestrel) taken as soon as possible after unprotected sex but optimally within 72 hours. This dose should be taken a second time, 12 hours after the first dose or a $1.5 \mathrm{mg}$ single levonorgestrel dose can substitute two $0.75 \mathrm{mg}$ doses $12 \mathrm{~h}$ apart up to 120 hours after unprotected intercourse; Yuzpe combined oral contraceptives (COC) regimen: $100 \mathrm{mcg}$ ethinyl estradiol plus $0.5 \mathrm{mg}$ of LNG (or $1.0 \mathrm{mg}$ norgestrel) taken as soon as possible after unprotected sex but optimally within 72 hours. This same dose should be taken a second time, 12 hours after the first dose. A single $10 \mathrm{mg}$ dose of mifepristone are effective for emergency contraception up to 120 hours after unprotected intercourse and Ulipristalacetat 30 $\mathrm{mg}$ and IUD insertion taken as soon as possible after unprotected sex but optimally within 120 hours (within 5 days) $[3,7,23]$.

In Ethiopia the need for emergency contraception (EC) was identified in the late nineteen nineties. In 2001, the Family Guidance Association of Ethiopia (FGAE) in collaboration with the Population Council initiated EC in selected youth center clinics in the country and study area. In this project, EC was provided in a repackaged brand so it would appeal to adolescents and youth in several ways for example, by cutting the cost of regular contraceptive pill, though the services were limited in scope and coverage [24]. However, after the survey, the availability and accessibility of EC were ensured in both public and private sectors of the country as well as in the study area. The following are the emergency contraceptives that are currently in use in the study area: (1) Combined Oral Contraceptive Pills (COCPs): an increased dose of combined oral contraceptives containing ethinyl estradiol and levonorgestrel (Yuzpe's regimen); (2) Progesterone Only Pills (POPs): high dose Progesterone Only Pills containing levonorgestrel; (3) Intrauterine Contraceptive Devices (Copper Releasing Intrauterine Contraceptive Devices) and (4) Mefipristone (Ru486): anti progesterone [24].

Reports from developed countries show that the use of EC varies from place to place [15] and the knowledge on correct use varies from $83 \%$ in Sweden [13] to less than $60 \%$ in developing countries [9]. One of the lowest percentages (10\%) was observed in a study done in Ethiopia at the Addis Ababa University and Unity University College, Ethiopia [4] on the knowledge, attitudes, and practices affecting the use of EC. Findings from several studies indicate that even women, who indicate that they know how to use EC, often report they have never used it. $[7,8,13,15,16]$. 
However, there are few studies which document the extent of emergency contraception use and the influencing factors on its use among university girls in Ethiopia. This study was carried out to assess EC use and its predictor factors among regular female students at Adama University. We hope that our study will provide baseline data to assist policy makers in developing appropriate evidence-based strategies to promote the need based use of emergency contraceptive methods amongst eligible individuals in Ethiopia.

\section{Methods}

This study was conducted in Adama University, located $100 \mathrm{Km}$ south east of Addis Abbaba. According to the information obtained from the Registrar Office of Adama University during the study period, Adama University had a total of 11788 students during the academic year of 2008 2009 of which 3,206 (27.2\%) were females. The University is located in Adama town where there is a busy transportation center. The city is situated along the road that connects Addis Ababa with Dire Dawa. A large number of trucks use this route to travel to and from the seaport of Djibouti. Additionally, the Addis Ababa-Djibouti railroad runs through Adama. The number of hotels, restaurants, pubs and clubs are increasing from time to time and in much the same way, the numbers of commercial sex workers and their clients are greater than before.

A cross-sectional study was conducted during the month of February 2009, using all regular undergraduate female students of Adama University as a source and randomly selected students as study participants.

The sample size was determined using a single population proportion formula assuming; 95\% level of confidence proportion of EC use of $73.4 \%$ [19], a design effect of 2 and non-response of $10 \%$. This gave a final sample size 660 female students. A two-stage sampling approach was used; where first 25 departments were selected randomly from the total 45 departments of Adama University (from four schools namely, School Of Business Administration, Management and Trade, School of Engineering and information Technologies, School of Humanities and Natural Science, School of Pedagogic and Vocational Teacher Education). Then, the total sample size was allocated to each department proportional to the number of female students per department. Secondly, from each respective department, participant students were selected proportional to their year of study using simple random sampling technique. The stratification of 
the year of the students was because the variable of interest in the study may vary across the year. Finally, 660 study participants who fulfilled the inclusion criteria were selected for the study.

The questionnaires contain five parts namely; socio-demographic characteristics, sexual and reproductive issues, practice of regular contraceptive use, knowledge EC, attitude of EC and utilization of EC.

The first part assessed information on the socio-demographic characteristics of the study participants which consisted of 9 questions. The second part assessed the sexual and reproductive issue and contained 10 questions. The questions were asked in the form requiring "Yes", "No" response and in multiple response form. Some of the questions were: (1) Ever had sexual experience? (2) Have you ever been pregnant? (3) What was the main reason for unwanted pregnancy? (4) Have you ever experienced induced abortion? All this questions were close ended (Yes, No and/or multiple choice questions). The third part contained practice of regular contraceptive use and knowledge of EC and consisted of 9 questions. The fourth part contained their attitudes and consisted of 6 questions. The fifth part assessed their prior EC practice and consisted of 6 questions.

Knowledge of EC was assessed by asking 8 questions. The eight questions evaluating the level of knowledge about EC were: (1) Which of these is an emergency contraceptive pill?, (2) How frequently EC can be used after unprotected sexual intercourse?, (3) Is EC is a method of early abortion?, (4) When taken early, can EC prevent sexually transmitted infections?, (5) Where can emergency contraception can be obtained? (6) When will emergency contraceptive pills be effective?, (7) When can IUCD be effective as an emergency contraceptive?,(8) How effective is it to use EC Pills in preventing pregnancy? . Each question was corresponds with "Yes" or "No" response and all "Yes" responses were given a value of " 1 " while "No" responses were given a value of " 0 ". The cut-off value used was taken from the mean of the sampled population which is $3.3 \pm 0.42$. Girls who scored the mean and above were labeled as having "good knowledge (knowledgeable)" while those who scored below the mean were labeled as having "poor knowledge" (inadequate knowledge).

Students' attitudes were measured using six items rated on a four-point Likert scale as (1) strongly disagree, (2) disagree, (3) agree and (4) strongly agree. The four items were: (1) EC causes a loss of confidence between regular partners, (2) It is a good idea to avail EC for all females., (c) The service in campus or nearby clinics is convenient to use EC (4) It is good to use EC after unsafe sexual intercourse (5) It is sinful to apply EC methods "(6) EC use may cause 
infertility in a woman. Attitude score was computed using the above six constructs whose theoretical value ranges from 6 to 24 . This scoring was subsequently reversed for negatively stated statements. Subsequently, respondents who scored above the average value of attitude score of the sampled population which is $14 \pm 1.8$ were labeled as having a positive attitude and respondents with an attitude score of less than the average were labeled as having a negative attitude.

The fifth part of the instrument required the students to state their prior experience with EC with either a "Yes' or "No" response and with multiple responses. It consisted of 10 structured questions. Some of the questions were: (1) Have you ever sexually active? (2) Have you ever engaged in unprotected sex? (3) Have you ever used emergency contraceptives? (4) Which methods have you used as EC? (5) In what time have you taken the method? The total numbers of question were 40 and the questions were adapted and modified according to the local situation from similar studies. The questions were either closed with "Yes", "No" responses or involved multiple responses.

The data was collected using a pre-tested structured self-administered questionnaire which was adapted from similar survey used by similar studies $[3,4,7]$. The questionnaire was prepared in English and translated into Amharic and then retranslated back to English to check its consistency. Internal consistency reliability estimate of cronbach's alpha was computed for the questionnaires of knowledge and attitudes towards EC after pretest and a value superior or equal to 0.7 was considered as reliable [25]. The cronbach's alpha coefficient of knowledge and attitude were 0.86 and 0.79 respectively.

Data were cleaned, checked for inconsistencies and missed values, coded and entered for analysis to SPSS (SPSS Inc. version 16.1., Chicago, Illinois). Bivariate analysis was used to see the unadjusted effects of each predictor. Variables that showed significant association in the bivariate analyses were fitted in to a multivariable logistic regression model to isolate the independent effects on EC use. All test were two sided and statistical significance was set at $p<0.05$.

Ethical permission was obtained from Adama University to conduct the study. All the study participants were informed about the purpose of the study and written consent was secured from all participants prior to the start of data collection. Privacy and confidentiality of information given by each respondent was maintained and names given were not recorded. With the help of assistants from each school, the selected students were taken to one hall, where they were 
informed about the purpose of the study, the importance of their participation and verbal consent was obtained. Based on their willingness to participate in the study, they were provided with the questionnaire and oriented on how to fill the questions. After they had completed filling in the questionnaire they, each, returned it to the facilitator (i.e. the respondents returned their questionnaires in person).

All filled questionnaires were checked for completeness, accuracy, clarity and consistency by the facilitator and investigator. Necessary corrections and changes were made in time. All supervision by the principal investigator throughout the data collection was carried out. This was to help identify problems that had to be addressed both on the questionnaires and with the data collectors.

\section{Results}

A total of 660 students were involved in the study. The mean ( \pm ) age was $20.2( \pm 1.7)$ years. Majority of the students (70.9\%) were Orthodox Christians, followed by Protestants and Muslims accounting for $14.4 \%$ and $13.0 \%$, respectively. Majority $(92.4 \%)$ of the respondents were living within the campus. Nearly half of $(47.7 \%)$ respondents were in their first year while the rest were second $(37.4 \%)$ and third year $(14.8 \%)$ students (table 1$)$.

Nearly one third of, 194 (29.4\%) respondents were ever sexually active, and out of which $37(19.1 \%)$ started sexual activity before the age 15 years and $144(74.2 \%)$ started sexual activity between 15 and 19 years of age.

Sixty three (32.5\%) of the previously sexually active girls and $9.5 \%$ of all girls had been pregnant at least once. Majority $(69.8 \%)$ of the pregnancies occurred between 15and 19 years of age and most of them (92\%) were unintended. Forgetting to take contraceptives $(41.4 \%)$, rape $(18.96 \%)$ and contraception failure $(13.8 \%)$ were the main reasons for unintended pregnancies .The majority ( $84.5 \%$ ) of pregnancies culminated in induced abortion; the reasons for the termination of the pregnancy were fear of interrupting schooling $(67.3 \%)$ and fear of family and community $(32.7 \%)$. A considerable proportion of induced abortions were performed by untrained persons $(55.1 \%)$ and some $(30.6 \%)$ were by trained personnel at clinics (table 2 ). 
Among the girls who had ever been sexually active only $16 \%$ used EC and from those girls who had unprotected sex only $26.7 \%$ used EC. EC and pills were the most common methods used (74.2\%). However, only $35.5 \%$ used EC within the recommended time limit (that means within $72 \mathrm{hrs}$ for ECPs and 5 days for IUCD) while the remaining $64.5 \%$ did not (Table 3). The most significant individuals influencing the use of EC were stated as: female friends $(54.3 \%)$, boyfriends (41.9\%) and health workers (35.5\%). Lack of knowledge (57.7\%), fear (37.4\%), and inconvenient service delivery $(32.5 \%)$ were mentioned as main reasons for not using EC (figure $1)$.

On bivariate analyses, age, year of study in campus, being married, religion, history of pregnancy, age at first sexual intercourse, previous use of contraceptives, knowledge about EC and attitude towards EC had statistically significant association with EC use $(P<0.05)$.

Accordingly, those who had age 20 years and above were 3.48 times more likely use EC compared to younger (COR:3.48; $95 \% \mathrm{Cl}=1.802-10.10$ ). Moreover, as year of study in campus increased, there was a relative increase in the use of emergency contraceptives COR $=3.25$ (95\% $\mathrm{Cl}=1.327,7.972)$ for year two, and $\mathrm{COR}=3.385(95 \% \mathrm{Cl}=1.57-9.901)$ for year three students. Participants who were married were 15.39 times more likely to use EC compared than their counterparts (COR: 15.39; $95 \% \mathrm{Cl}=7.14-33.19$ ). Similarly female students who started sexual intercourse at late age; that means age 20 and above, were found to be 2.368 times more likely to practice EC than their counter parts who started sexual activity earlier COR $=2.368$ (95\% $\mathrm{Cl}=1.598,4.105)$. Besides, emergency contraceptive use was higher among the Protestants compared to Orthodox and Muslim religions ( $\mathrm{COR}=4.05 ; 95 \% \mathrm{Cl}=1.762,9.32)$

Respondents who had a history of pregnancy were found 4.9 times more likely to utilize EC than their counterparts $\mathrm{COR}=5.68(95 \% \mathrm{Cl}=2.48,13.007)$ (table 4). And emergency contraceptive utilization was significantly higher among the respondents who had previously used regular contraceptives than those who had no experience of regular contraceptive use COR $=3.28$ (95\% $\mathrm{Cl}=1.49,7.206)$.

Emergency contraceptive use was significantly higher among the respondents who had a positive attitude to $\mathrm{EC}$ than those who had negative attitude $\mathrm{COR}=5.867(95 \% \mathrm{Cl}: 1.764,19.51)$. On the contrary, those who have poor (lacked) knowledge about EC were $99 \%$ less likely to use EC (COR: $0.01 ; 95 \% \mathrm{Cl}=0.057-0.209$ ) (table 4 ). 
On the multivariable logistic model after adjusting for other covariates, those who had age 20 years and above were 2.4 times more likely use EC compared to those younger (AOR:2.372; $95 \% \mathrm{Cl}=1.102-7.246)$. Similarly, those who were married were 9.3 times more likely to use EC compared than their counterparts (AOR: 9.25; 95\% Cl = 2.538-20.73). On the contrary, those who have lacked knowledge about EC were $90 \%$ less likely to use EC (AOR: $0.09 ; 95 \% \mathrm{Cl}=$ 0.021-0.189).Respondents who had experience of regular contraceptive use were 1.95 times more likely to use EC than other counterparts (AOR: 1.953; $95 \% \mathrm{Cl}=1.72-6.345$ ) (table 4).

\section{Discussion}

Our results show that utilization of EC was low; correct use was even lower. The age of the respondents, marital status, and knowledge about EC and previous use of regular contraceptives as variables were found to be major predictors of EC utilization.

In this study it was found that $26.7 \%$ of those who had unprotected sex used EC, which is similar to the report of studies among university students in Addis Ababa and Jamaica [4,21] and a relatively higher proportion of EC practice was reported from South Africa and Nigeria [7,8]. The possible reasons for a low EC practice observed in this study might be related to the lower proportion of sexually active students in Adama university (29\%); compared to (57\%) at the university in South Africa and (63\%) at university in Nigeria. It might also be due to a lack of knowledge of EC observed in this study.

Girls who were older were found to have used EC more than their younger counterparts. This finding is consistent with the study conducted in AAU, Ethiopia, South Africa, Nigeria and France, which reported that age has a significant effect on the practice of EC, where older age groups are more likely to use EC when compared to younger age groups [4,7-9]. Younger girls may have less information about the proper use of EC due to the fact that they are newly enrolled in university and may not have received this information in prior schooling

In the current study, marital status showed a significant association with use of EC. This finding is comparable to the reports of studies conducted in Addis Ababa University [3] and among women of reproductive age groups in Mongolia which showed that married female students were more likely to practice EC than unmarried girls [9]. The effect of marital status and increment in age on EC use might be linked to issues like decreased fear of being seen by others for those 
older and married girls. In addition, better exposure to information, maturity and heightened awareness of the consequences of unintended pregnancy held by girls as they get older and engaged in marital status that means older/married women would have less severe consequences from unintended pregnancy than would their younger unmarried counterparts $[4,13,14,18]$.

In this study, good knowledge of EC was a significant predictor of their use, which is in agreement with reports of studies conducted in Nigeria [8], Cameroon [13] and Sweden [14] where knowledge of EC was significantly associated with increased likelihood of using them. The study also showed that experience of using regular contraception had a significant association with EC use, where those who used regular contraceptive methods used EC more compared to those who had no previous experience of regular contraceptive use. This finding is inconsistent with the reports of other studies which showed that a lower proportion of girls with experience of regular contraceptive use used EC $[9,14]$. This inconsistency might be explained by the differences in level of use of regular contraceptives in the studies which were not further explored.

Although the findings of this study may not be generalized to girls who are out of university, it has demonstrated the sexual and reproductive health problems faced by girls in Adama University. However, the findings may not be representative of all higher learning institutions of Ethiopia as the socio-cultural situations around the different Universities in Ethiopia vary greatly. Although the anonymous self-administered questionnaire was used, the possibility of social desirability bias cannot be totally eliminated as the study touches sensitive issues. In general this study came up with findings which have a policy implication of reducing the short and long term effects of unintended pregnancy among young girls in higher learning institutions. The need for increasing the knowledge of university girls about EC and availing youth friendly sexual and reproductive health services is implicated.

\section{Conclusion}

In general this study came up with findings which have a policy implication of reducing the short and long term effects of unintended pregnancy among young girls in higher learning institutions. The need for increasing the knowledge of university girls about EC and availing youth friendly sexual and reproductive health services is implicated. 


\section{Competing interests}

The authors declare they have no competing interests.

\section{Authors' contribution}

ICMJE authorship criteria are met. Dejene T: Concept and design, data collection and analysis, interpretation of data, initial draft, review of literature and final write up. Tsion A: Critical review of initial draft and article and final write up. Tefera B: Critical review of draft and article and final write up.

\section{Tables and figure}

Table 1: Socio-demographic characteristics of female students, Adama University, Central Ethiopia, February, 2009

Table 2: Reproductive history of female Adama University students, South Eastern Ethiopia, February, 2009

Table 3: Emergency contraceptive Practice among female students of Adama University, Adama, Central Ethiopia, February, 2009

Table 4: Predictors of emergency contraceptive use among Adama University female students, Central Ethiopia, February, 2009

Figure 1: Reasons for not using contraceptives among sexually active students of Adama University

\section{Acknowledgments}

Jimma University is highly acknowledged for financial support. And we are very grateful to regular female students at Adama University for sacrificing their time and for actively participating in this study. 


\section{References}

1. Tadesse E, Yoseph S, Gossa A. Illegal abortion in five hospitals in Addis Ababa. Ethiopian Medical J ournal. 1994; 32 (4):283-84

2. Central statistics authority (CSA), Ethiopian Demographic and Health Survey. Addis Ababa, Ethiopia 2005

3. J osaphat Kayogoza Byamugisha. User and provider perspectives emergency contraception among young people in Uganda, 2007, Kampala and Stockholm. (PHD thesis) available: www.nfog.org/theses/J osaphat\% 20Kayogoza.pdf

4. Wegene T, Fikre E. Knowledge, attitude and practice on Emergency Contraceptives among female students at higher educations in Addis Ababa. Ethiopian J ournal Health Development. 2007;21(2): 111-116

5. Solomon W, Mesganaw F. Unintended pregnancy and induced abortion in a town with accessible family planning service, the case of Harar in Eastern Ethiopia. Ethiopian Journal of Health Development. 2006; 20(2):72-138

6. Fantahun M, Chala F, Lola M. knowledge, Attitude and practice of family planning among high school students in North Gonder. Ethiopian Medical J ournal. 1995;33(1): 21-29. This article on PubMed

7. MI Manena-Netshikweta. Knowledge, perception and attitude regarding contraceptives among secondary school learners in the Limpopo province, November 2007, South Africa. (PHD thesis). available: uir.unisa.ac.za/bitstream/10500/1977/1/thesis. pdf

8. Michael E Aziken, Patrick I Okonta and Adedapo B A Ande. Knowledge and Perception of Emergency Contraception among Female Nigerian Undergraduates. International Family Planning Perspectives. 2003; 29(2):84-87. This article on PubMed 
9. Altankhuyagiin G, Jane F, James B. Determinants of current contraceptive use and method choice in Mongolia. Journal of Biosocial Science. 2007:1-17, Cambridge University Press

10. Aira V, Andres H. Family planning among university students in Finland, April 14, 2007, University of Tampere. Accessible http:/acta.uta.fi

11. Ahmed A, Nugusse D. Youth reproductive health problems and service in West Harrgie Ethiopia April 29, 2004

12. CORHA. Assessment of the reproductive health situation/problems of the students in Addis Ababa, Bahir Dar, Jimma, and Mekele Universities, Addis Ababa, 2000

13. Larsson M, Aneblom G, Eurenius K, Westerling R, Tydén T. The Adoption of a New Contraceptives methods- surveys and intervention regarding emergency contraception. Acta Obstetricia et Gynecologica Scandinavica. 2006;85( 9): 1142-1143. This article on PubMed

14. H Goulard et al. Contraceptive failures and determinants of emergency contraception use. Contraception. 2006 Sep; 74(3):208-13. This article on PubMed

15. IPPFAR. Unsafe Abortion and post abortion family planning in Africa, The Mauritius Conference. 2000:1-10

16. Foster DG, Harper CC, Bley JJ, Mikanda JJ, Induni M, Saviano EC, Stewart FH. Knowledge of emergency contraception among women aged 18 to 44 in California. Am J Obstet Gynecol. 2004 Jul; 191(1):150-6. This article on PubMed

17. Kongnyuy EJ, Ngassa P, Fomulu N, Wiysonge CS, Kouam L, Doh AS. A survey of knowledge, attitudes and practice of emergency contraception among university students in Cameroon. BMC Emerg Med. 2007 J ul 17; 7:7. This article on PubMed

18. Haile A, Fesseha N. Emergency contraception: potential clients' and Providers'perspective. Ethiopian J ournal of Health Sciences. 2004;16(1): 1-8 
19. Zeleke G, Zebenay Z, Weldegerima B. Knowledge Attitude and Practice of Emergency Contraceptives in Bahir Dar University Female Students. Ethiopian J ournal of Reproductive Health. 2009; 3: 59-64

20. Seife M, Fikre E. Assessment of level of awareness and utilization of emergency contraception, among college female students in Oromia Regional state, Arsi Zone, Asella, South-East Ethiopia. Master thesis, AAU), June, 2007

21. Sorhaindo A, Becker D, Fletcher H, Garcia SG. Emergency contraception among university students in Kingston, Jamaica: A survey of knowledge, attitude and practice. Middle East Fertility Society J ournal. 2002;66 (4):261-8

22. The Consortium of Reproductive Health Associations in Ethiopia, Bi-annual information Bulletin of the consortium of Reproductive Health Associations (CORHA). 2005; 4(2)

23. von Hertzen J, Piaggio G, Ding J, Chen J, Song S, Bartfai G, et al. Low dose mifepristone and two regimens of levonorgestrel for emergency contraception: a WHO multicentre randomized trial. Lancet. 2002 Dec 7;360 (9348):1803-10. This article on PubMed

24. Ethiopian Society of Obstetricians and Gynecologists (ESOG), Ministry of Health (FMOH) and ECafrique. A training curriculum for mid-level health workers in Ethiopia. Addis Ababa, Ethiopia May 2005, Newsletter volume I Number II, Available on: www.esog@ethionet.et

25. J oseph A, Rosemary R. Calculating, interpreting, and Reporting Cronbach's Alpha Reliability Coefficient for Likert-Type Scales, Midwest Research to Practice Conference in Adult, Continuing, and Community Education 2003, 82-88 
Table1: Socio-demographic characteristics of female students, Adama University, Central Ethiopia, February, 2009

\begin{tabular}{|c|c|c|}
\hline Socio demographic characteristics $n=660$ ) & Number & Percent (\%) \\
\hline \multicolumn{3}{|l|}{ Age } \\
\hline $15-19$ & 220 & $33 . .3$ \\
\hline $20-24$ & 427 & 64.7 \\
\hline $25-29$ & 7 & 1.1 \\
\hline$>30$ & 6 & 0.9 \\
\hline \multicolumn{3}{|l|}{ Year of study } \\
\hline Year I & 315 & 47.7 \\
\hline Year II & 247 & 37.5 \\
\hline Year III & 98 & 14.8 \\
\hline \multicolumn{3}{|l|}{ Residence } \\
\hline Campus & 610 & 92.4 \\
\hline Out of Campus & 50 & 7.6 \\
\hline \multicolumn{3}{|l|}{ Religion } \\
\hline Orthodox & 468 & 70.9 \\
\hline Muslim & 86 & 13.0 \\
\hline Protestant & 95 & 14.4 \\
\hline Catholic & 7 & 1.1 \\
\hline Others & 4 & 0.6 \\
\hline \multicolumn{3}{|l|}{ Ethnicity } \\
\hline Amhara & 259 & 39.2 \\
\hline Oromo & 243 & 36.8 \\
\hline Tigrie & 52 & 7.9 \\
\hline Guragie & 61 & 9.2 \\
\hline woliata & 41 & 6.4 \\
\hline Others & 4 & 0.5 \\
\hline \multicolumn{3}{|l|}{ Marital status } \\
\hline Single & 597 & 90.5 \\
\hline Married & 61 & 9.2 \\
\hline Divorced & 2 & 0.3 \\
\hline \multicolumn{3}{|l|}{ Number of children } \\
\hline None & 629 & 95.3 \\
\hline One & 24 & 3.6 \\
\hline Two & 7 & 1.1 \\
\hline
\end{tabular}


Table 2: Reproductive history of female Adama University students, South Eastern Ethiopia, February, 2009

\begin{tabular}{|c|c|c|}
\hline Variable & Frequency & Percent (\%) \\
\hline \multicolumn{3}{|l|}{ Sexually Active $(n=660)$} \\
\hline Yes & 194 & 29.4 \\
\hline No & 466 & 70.6 \\
\hline \multicolumn{3}{|c|}{ Unprotected sexual intercourse( $n=194)$} \\
\hline Yes & 116 & 59.8 \\
\hline No & 78 & 40.2 \\
\hline \multicolumn{3}{|c|}{ Age of first sexual intercourse $(n=194)$} \\
\hline Younger than 15 years & 37 & 19.1 \\
\hline $15-19$ years & 144 & 74.2 \\
\hline $20+$ years & 13 & 6.7 \\
\hline \multicolumn{3}{|l|}{ Ever been pregnant $(n=194)$} \\
\hline Yes & 63 & 32.5 \\
\hline No & 131 & 67.5 \\
\hline \multicolumn{3}{|l|}{ Age at first pregnancy $(n=63)$} \\
\hline$<15$ years & 18 & 28.6 \\
\hline $15-19$ years & 44 & 69.8 \\
\hline $20+$ years & 1 & 1.6 \\
\hline \multicolumn{3}{|l|}{ Unintended pregnancy $(n=63)$} \\
\hline Yes & 58 & 92.1 \\
\hline No & 5 & 7.9 \\
\hline \multicolumn{3}{|c|}{ Reasons for unintended pregnancy $(n=58)$} \\
\hline Forget to take contraceptive & 24 & 41.4 \\
\hline Rape(Forced to have sex) & 11 & 18.96 \\
\hline Contraceptive failure & 8 & 13.8 \\
\hline Rapture of condom & 7 & 12.0 \\
\hline Lack of knowledge about EC & 5 & 8.6 \\
\hline Abandoned (pressure) by partner & 3 & 5.2 \\
\hline \multicolumn{3}{|c|}{ Experience of induced abortion $(n=58)$} \\
\hline Yes & 49 & 84.5 \\
\hline No & 7 & 12.1 \\
\hline I don't know & 2 & 3.4 \\
\hline \multicolumn{3}{|l|}{ Place of induced abortion $(n=49)$} \\
\hline Untrained abortionist & 27 & 55.1 \\
\hline Clinics & 15 & 30.6 \\
\hline Self-infliction & 7 & 14.3 \\
\hline \multicolumn{3}{|c|}{ Reasons for having induced abortion $(n=49) *$} \\
\hline Fear of discontinuing school & 33 & 67.3 \\
\hline Fear of parents and family & 16 & 32.7 \\
\hline Economic problems & 6 & 12.2 \\
\hline
\end{tabular}


Table 3: Emergency contraceptive Practice among female students of Adama University, Adama, Central Ethiopia, February, 2009

\begin{tabular}{lcc}
\hline Characteristics & Number & Percent (\% \\
\hline Ever Used EC among sexual active $(\mathbf{n = 1 9 4 )}$ & 31 & 16 \\
Yes & 163 & 84 \\
No & & \\
Ever Used EC among unprotected sex(n= 116) & 31 & 26.7 \\
Yes & 85 & 73.3 \\
No & & \\
Methods used as EC $(\mathbf{n = 3 1 )}$ & & \\
EC pills & 23 & 74.2 \\
IUCD & 2 & 6.4 \\
I don't know/remember & 6 & 19.4
\end{tabular}

Place obtained $(\mathbf{n}=31) *$

Pharmacy 15

48.4

Government health institutions 12

38.7

Private clinics

$4 \quad 12.9$

Time EC were used $(\mathbf{n}=\mathbf{3 1})$

Correct(with in $72 \mathrm{hrs}$ for ECPs \& 120hrs for IUCD) $\quad 11$

Do not(out of the 72 hrs ECPs \& 120 for IUCD) $\quad 20$

How many times used $(\mathrm{n}=31)$

Once

15

48.4

Two and above

6

19.4

Not remember

$8 \quad 25.8$

I don't know

2

6.4

Told to use EC (significant others) $(\mathbf{n}=31)$ *

Friends female/peers

54.3

Boyfriends/partner

13

41.9

Health worker

11

35.5

Teachers in the class

2

6.5

Ever Used EC ( $n=194)$ means those that used ever EC from previously sexually active girls and Ever Used EC $(n=116)$ means those who have ever used EC from those girls who had ever engaged in unprotected sexual intercourse 
Table 4: Predictors of emergency contraceptive use among Adama University female students, Central Ethiopia. February, 2009

\begin{tabular}{|c|c|c|c|c|}
\hline \multirow[t]{2}{*}{ Predictors } & \multicolumn{2}{|c|}{$\begin{array}{c}\text { Used Emergency } \\
\text { Contraceptive }\end{array}$} & \multirow[t]{2}{*}{ COR $(95 \% \mathrm{Cl})$} & \multirow[t]{2}{*}{ AOR(95\% Cl) } \\
\hline & Yes & No & & \\
\hline \multicolumn{5}{|l|}{ Age } \\
\hline $15-19$ years & $6(2.7)$ & $214(97.3)$ & 1.00 & 1.00 \\
\hline $20+$ and above & $25(5.7)$ & $415(94.3)$ & $3.481(1.802,10.10) 2$ & $2.372(1.102-7.246)^{1}$ \\
\hline \multicolumn{5}{|l|}{ Year of study } \\
\hline year one & $7(2.2)$ & $308(97.8)$ & 1.00 & 1.00 \\
\hline year two & $17(6.9)$ & $230(93.1)$ & $3.252(1.327-7.972)^{1}$ & $3.147(0.944-10.485)$ \\
\hline \multicolumn{5}{|l|}{ Religion } \\
\hline Orthodox & $13(2.8)$ & $455(97.2)$ & 1.00 & 1.00 \\
\hline Muslim & $7(8.1)$ & 79(91.9) & $1.31(0.404-3.53)^{1}$ & $0.176(0.080-1.86)$ \\
\hline Protestant/Catholic & $11(10.4)$ & $95(89.6)$ & $4.05(1.762-9.32)^{1}$ & $1.189(0.762-5.417)$ \\
\hline \multicolumn{5}{|l|}{ Marital status } \\
\hline Never married/single & $14(2.2)$ & $583(97.7)$ & 1.00 & 1.00 \\
\hline Married & $17(29.0)$ & $46(73.0)$ & $15.39(7.14-33.19)^{3}$ & $9.254(2.538-20.73)^{3}$ \\
\hline \multicolumn{5}{|l|}{ Number of children } \\
\hline \multicolumn{5}{|l|}{$\begin{array}{l}\text { Age of first sexual } \\
\text { intercourse }\end{array}$} \\
\hline Younger than 15 years & $3(8.1)$ & $34(91.9)$ & 1.00 & 1.00 \\
\hline 15-19 years & $21(14.6)$ & $123(85.4)$ & $1.657(1.23,4.49)$ & $1.720(0.946,2.959)$ \\
\hline $20+$ years & $7(53.8)$ & $6(46.2)$ & $2.368(1.598,4.105)^{1}$ & $2.38(0.869,1.228)$ \\
\hline \multicolumn{5}{|l|}{ History of pregnancy } \\
\hline yes & $21(32.3)$ & $44(67.7)$ & 1.00 & 1.00 \\
\hline & $10(7.8)$ & $119(92.2)$ & $5.680(2.480-13.007)^{1}$ & $3.32(0.780-12.007$ \\
\hline \multicolumn{5}{|l|}{ Ever used RC } \\
\hline No & $13(10.1)$ & $114(89.9)$ & 1.00 & 1.00 \\
\hline $\begin{array}{l}\text { yes } \\
\text { Knowledge of EC }\end{array}$ & 18(26.9) & $49(73.1)$ & $3.278(1.49-7.206))$ & $1.953(1.72-6.345))$ \\
\hline Good knowledge & $23(29.1)$ & $54(71.1)$ & 1.00 & 1.00 \\
\hline $\begin{array}{l}\text { Poor knowledge } \\
\text { Attitude }\end{array}$ & $8(3.5)$ & $223(96.5)$ & $0.10(0.057-0.209))$ & $0.09(0.041-0.189))$ \\
\hline Negative & $6(2.4)$ & $240(97.6)$ & 1.00 & 1.00 \\
\hline Positive & $25(6.8)$ & $389(93.2)$ & $5.867(1.764,19.51))$ & $2.567(0.564,6.43)$ \\
\hline
\end{tabular}

RC: Regular contraceptive, EC: Emergency contraceptive, $1 \mathrm{P}<0.05,2 \mathrm{P}<0.01,3 \mathrm{P}<0.001$, COR= Crude odds Ratio, AOR $=$ Adjusted odds ratio 


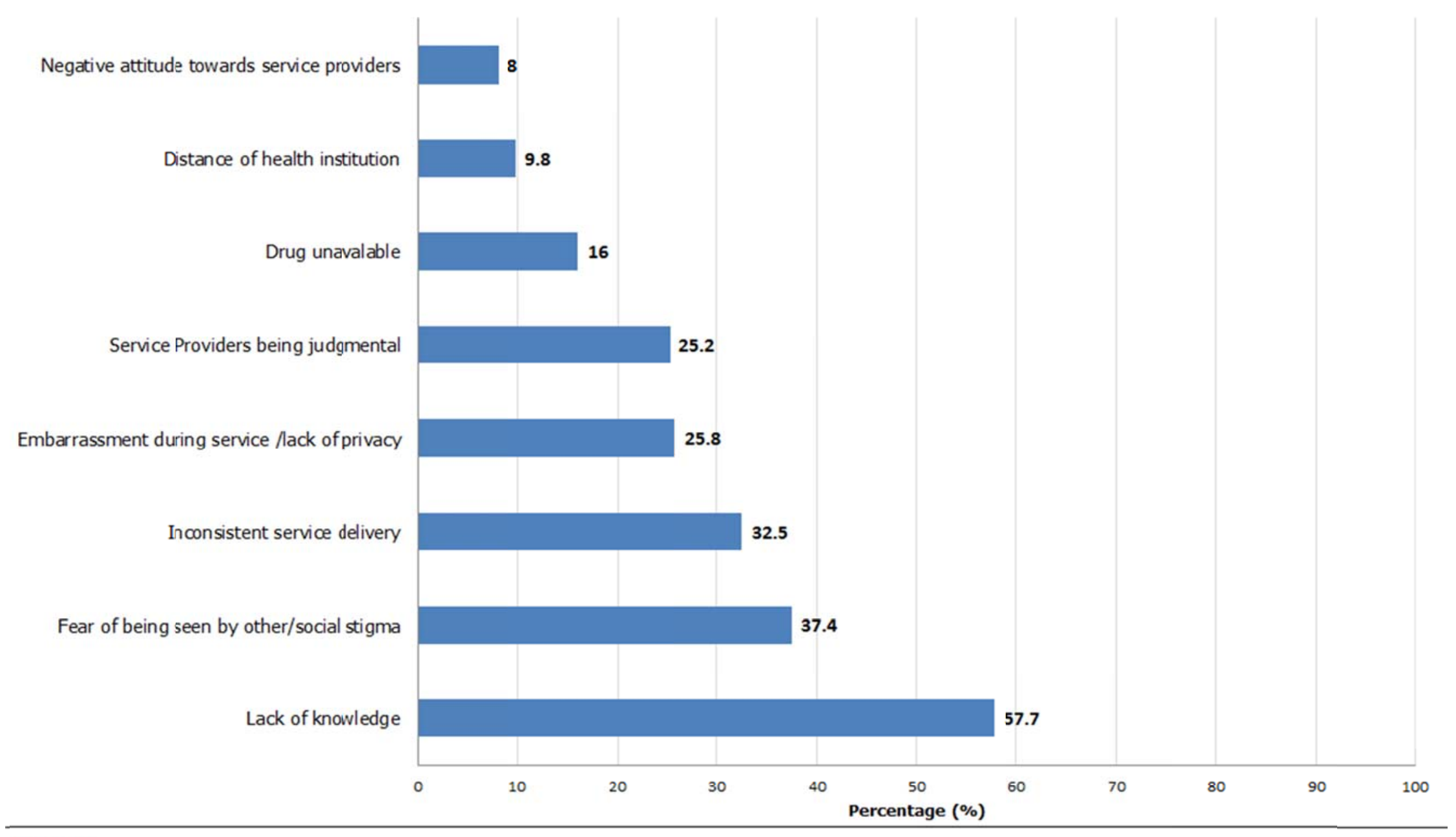

Figure 1

Reasons for not using contraceptives among sexually active female students of Adama University, Central Ethiopia, February 2009 